\title{
Pengaturan Energy Hybrid Tenaga Surya dan PLN pada Pompa Aerasi Tambak Udang Berbasis PID Control
}

\author{
Nuryanti, ST.MSc ${ }^{1}$, Ir. Bolo Dwiartomo, M.Eng. ${ }^{2}$, Amalia Nur Hikmah, A.Md.T ${ }^{3}$ \\ ${ }^{1}$ Jurusan Teknik Otomasi Manufaktur dan Mekatronika, Politeknik Manufaktur Bandung, Bandung 40135 \\ E-mail:nuryanti@polman-bandung.ac.id \\ ${ }^{2}$ Jurusan Teknik Otomasi Manufaktur dan Mekatronika, Politeknik Manufaktur Bandung, Bandung 40135 \\ E-mail : bolodwiartomo@polman-bandung.ac.id \\ ${ }^{3}$ Jurusan Teknik Otomasi Manufaktur dan Mekatronika, Politeknik Manufaktur Bandung, Bandung 40135 \\ E-mail : amalia.nhkm@gmail.com
}

\begin{abstract}
ABSTRAK
Perpaduan energi terbarukan dengan PLN yang telah ada memerlukan sistem kendali agar penggunaan energi dapat efisien. Oleh karena itu, dibuat sistem kendali yang mengatur kerja pompa agar tidak hanya bekerja secara on-off tetapi juga bervariasi kecepatannya berdasarkan kandungan oksigen terlarut yang diperlukan, maka dibuat suatu sistem kendali PID dengan metode Ziegler Nichols yang dilengkapi dengan input sensor oksigen dengan set point $4 \mathrm{mg} / \mathrm{L}$ dan aktuator berupa 2 pompa yang masing-masing bersumber dari PLTS dan PLN yang dihybrid secara otomatis berdasarkan waktu pemenuhan kadar DO. Pompa yang digerakkan berbasis motor DC sehingga dari PLTS dapat langsung menjalankan motor sedangkan dari PLN ada DC regulator sebelum masuk ke pompa. Kala kadar DO di bawah set point, maka pompa dari PLTS akan bekerja terlebih dahulu, namun jika sampai waktu 30 detik belum mencapai setpoint maka pompa yang digerakkan oleh listrik PLN akan bekerja untuk membantu pompa dari PLTS hingga tercapai setpoint-nya. Hasil dari penelitian ini mendapatkan karakteristik PID pada set point DO $4 \mathrm{mg} / \mathrm{L}$ yaitu dengan nilai $\mathrm{Kp} 0.812$, Ki 0,002, dan $\mathrm{Kd} \mathrm{0,7}$, overshoot $0 \%$, rise time $25.6 \mathrm{~s}$, dan settling time 32.6 s, serta sinkronisasi otomatis sumber daya PLN dan PLTS dengan efisiensi daya minimum 10.3\% dan efisiensi daya maksimum 57\%.
\end{abstract}

Kata Kunci

PLN, PLTS, Hybrid, Otomatis, PID

\section{PENDAHULUAN}

Penggunaan energi terbarukan sedang berkembang. Namun, nilai investasi yang diperlukan masih cukup tinggi [1]. Sumber energi yang digunakan dalam tambak udang yang kini menjadi sumber mata pencaharian beberapa petani tambak umumnya masih diperoleh dari PLN untuk mengaktifkan seluruh pompa yang ada di tambak sebagai kendali oksigen terlarut (Dissolved Oxygen/DO) atau metode aerasi. Seperti diketahui dalam pembudidayaan udang diperlukan kondisi lingkungan air yang mengandung oksigen minimal 4ppm [2]. Pada lingkungan tempat penambak udang terdapat sumber energi matahari yang berlimpah. Nilai investasi pengadaan solar panel pada system aerasi masih cukup tinggi dimana untuk ukuran kolam ikan 50mx50m dengan kedalaman $1.5 \mathrm{~m}$ maka diperlukan pasokan daya $403 \mathrm{~W}$ untuk mendapatkan kandungan DO 4ppm selama 24 jam pompa menyala. Sedangkan jika 12 jam dibutuhkan daya $806 \mathrm{~W}$ [2]. Jika nilai investasi pengadaan PLTS Rp 10000/Watt-peak[3], maka membutuhkan dana untuk kebutuhan daya $806 \mathrm{~W}$ sekitar Rp 9.000.000 hingga Rp 13.000.000. Oleh karena itu mengurangi biaya investasi diperlukan pemanfaatan energi terbarukan yang digabungkan (hybrid) dengan sumber listrik PLN. Sehingga dengan nilai investasi yang tidak terlalu besar namun dapat mengurangi penggunaan listrik PLN. Penggunaan energy hybrid ini membutuhkan suatu pengaturan/manajemen energi otomatis agar lebih efisien[4]. Penggunaan energi hibrid antara energi surya dan PLN seperti yang telah dilakukan oleh Rachmad Ikhsan dan Ali Basrah [5]. Namun, pada umumnya sistem otomasinya masih berupa kendali on-off yang aktif jika kandungan oksigen terlarut kurang dari $4 \mathrm{mg} / \mathrm{L}$ seperti yang dilakukan oleh Ari Fiyanti dan Mardhiya. Dengan sistem on/off ini maka pompa hanya akan bergerak di satu kecepatan yaitu kecepatan maksimumnya [6]. Sedangkan, Deni Ramdhani juga menggunakan kendali on-off kerja pompa disesuaikan dengan kadar DO ditambah dengan monitoring suhu dan $\mathrm{pH}$ [7]. Dalam penelitian ini dikembangkan sistem kendali PID Ziegler Nichols dengan keunggulan berupa kecepatan pompa yang dapat divariasikan sesuai dengan kebutuhan oksigen pada tambak secara otomatis dan bersumber daya hybrid PLN dan PLTS.

\section{BATASAN MASALAH}

Batasan dalam penelitian ini sebagai berikut.

a. Sistem bukan merupakan skala tambak, melainkan prototype tambak udang dengan ukuran kedalaman 1 meter dan diameter $0,4 \mathrm{~m}$.

b. Parameter lain selain oksigen terlarut tidak dikendalikan. 


\section{PERANCANGAN SISTEM}

Metodologi tahapan penelitian ini ditunjukkan pada Gambar 1. Pertama adalah melakukan identifikasi masalah melalui penelitian di tambak. Kedua adalah studi literatur yang bersumber dari buku elektronik, jurnal, dan penelitian terkait lainnya sebagai solusi atas masalah yang telah diidentifikasi. Setelah melakukan studi literatur, penulis merancang arsitektur sistem. Kemudian merealisasikan dan melakukan pengujian sistem, evaluasi serta melakukan perbaikan.

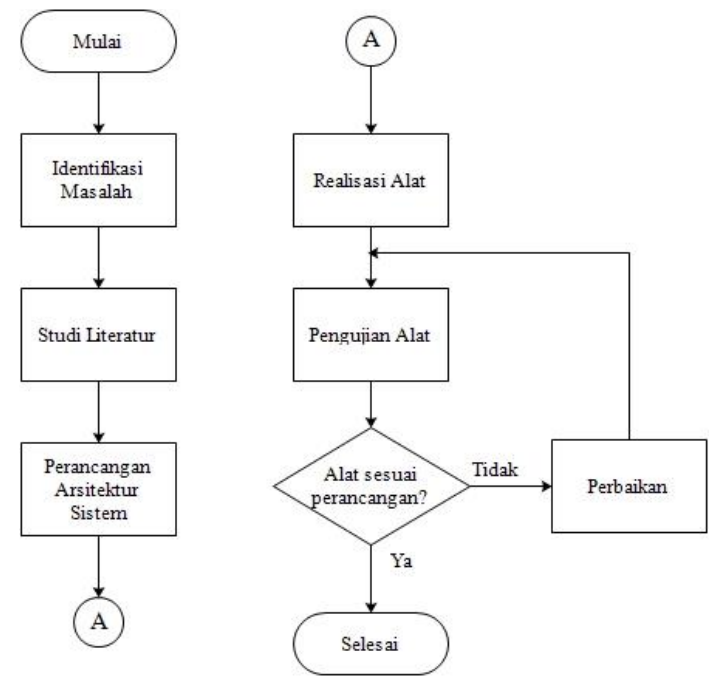

Gambar 1. Metodologi Penelitian Sistem

Perancangan arsitektur sistem meliputi arsitektur sistem secara keseluruhan dan diagram blok kendali yang ditunjukkan pada Gambar 2. Arsitektur Sistem dan Gambar 3. Diagram Blok Kendali.

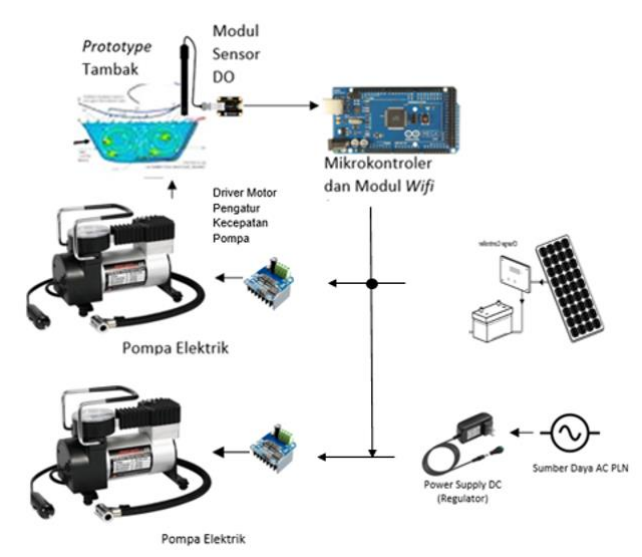

Gambar 2. Arsitektur Sistem

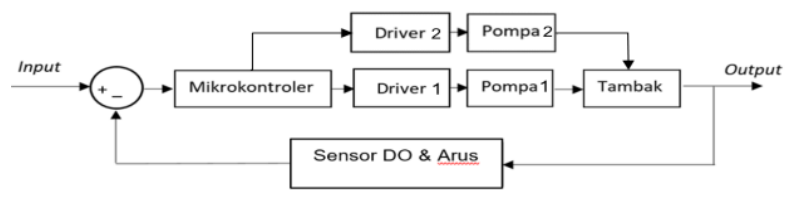

Gambar 3. Diagram Blok Kendali
Sistem dimulai dari modul sensor DO analog (Analog Dissolved Oxygen) yang telah dikalibrasi dengan DO meter mendeteksi jumlah oksigen yang terlarut di dalam air tambak, yang kemudian diolah dengan mikrokontroler Arduino Mega 2560 yang telah diprogram dimulai dengan pembacaan kadar DO, pembacaan arus pada aki (penyimpanan daya dari solar panel) menggunakan sensor ACS 712, kemudian 2 kendali PID menggunakan driver BTS7960 yang dihubungkan dengan 2 pompa kompresor elektrik, pompa pertama dihubungkan dengan sumber daya dari solar panel yang disimpan pada aki, pompa kedua dihubungkan dengan sumber daya dari PLN menggunakan power supply 12V 10 A. Ketika sistem dijalankan, pertama kali sistem akan melakukan pembacaan kadar DO. Ketika kadar DO kurang dari 4 $\mathrm{mg} / \mathrm{L}$, pembacaan sensor arus pada penyimpanan sumber daya PLTS diaktifkan. Ketika kadar DO kurang dari $4 \mathrm{mg} / \mathrm{L}$ dan arus pada penyimpanan (aki) kurang dari 1A, maka pompa kedua yang bersumber dari PLN akan aktif dan menjalankan program kendali PID dan menon-aktifkan driver pompa pertama yang bersumber dari PLTS hingga penuh. Ketika kadar DO telah mencapai Set Point (4 mg/L), maka kedua pompa tidak aktif. Ketika kadar DO kurang dari $4 \mathrm{mg} / \mathrm{L}$, maka driver pompa solar akan aktif kembali, mendeteksi arus, ketika arus lebih dari $1 \mathrm{~A}$, maka pompa solar akan aktif untuk memasok oksigen, dan jika selama 30 detik oksigen yang dipasok dari pompa solar masih kurang dari 4 $\mathrm{mg} / \mathrm{L}$, maka pompa yang bersumber dari PLN akan aktif. Tahapan sistem tersebut ditunjukkan pada Gambar 4.
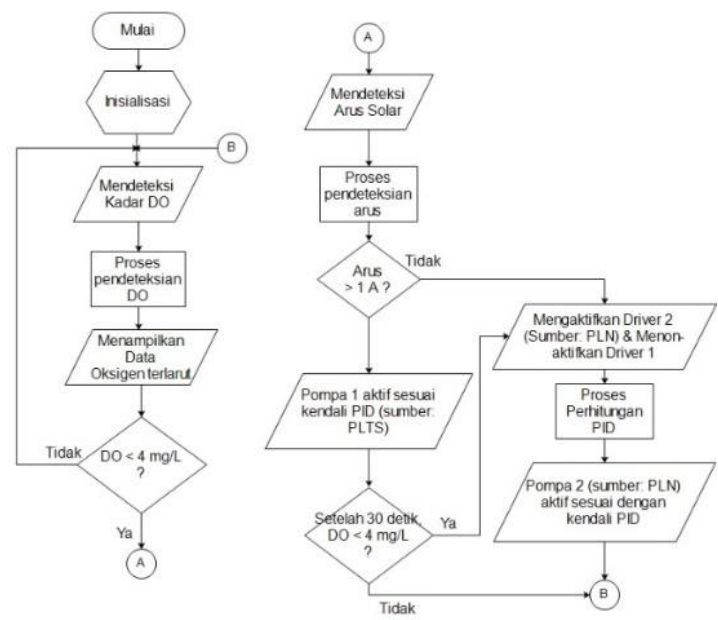

Gambar 4. Diagram Alir Sistem

\section{HASIL PENGUJIAN SISTEM}

\subsection{Hasil Kalibrasi dan Pengujian Pembacaan Sensor DO}

Sensor DO yang digunakan telah dikalibrasi dengan grafik linearitas pengukuran kadar DO menggunakan DO Meter terhadap tegangan keluaran sensor DO pada sistem. Hasil kalibrasi ditunjukkan pada Gambar 5 yang menghasilkan persamaan:

$$
y=0,1645 x+0,0567
$$


Tabel 1. Hasil Pengukuran DO Meter

\begin{tabular}{cccc}
\hline No. & $\begin{array}{c}\text { Pengukuran DO } \\
\text { dengan Sensor DO } \\
(\mathbf{m g} / \mathbf{L})\end{array}$ & $\begin{array}{c}\text { Pengukuran DO } \\
\text { dengan DO Meter } \\
(\mathbf{m g} / \mathbf{L})\end{array}$ & $\begin{array}{c}\text { Error } \\
(\%)\end{array}$ \\
\hline $\mathbf{1}$ & 3,48 & 3,50 & 0,57 \\
$\mathbf{2}$ & 4,61 & 4,60 & 0,21 \\
$\mathbf{3}$ & 4,93 & 4,90 & 0,61 \\
$\mathbf{4}$ & 5,44 & 5,40 & 0,74 \\
$\mathbf{5}$ & 6,32 & 6,30 & 0,31 \\
\hline \multicolumn{4}{c}{ Rata-rata $(\%)$} \\
\hline
\end{tabular}

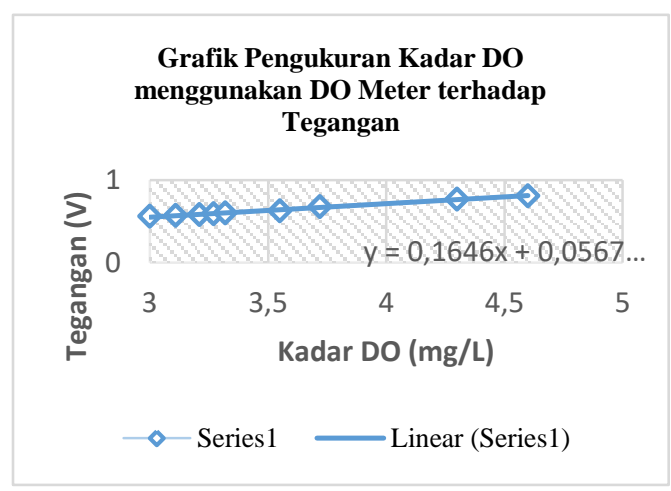

Gambar 5. Grafik Pengukuran Kadar DO terhadap Tegangan

Hasil pengujian pembacaan sensor DO dengan DO Meter (Kadar DO sebenarnya) ditunjukkan pada Tabel 1. Berdasarkan data pada tabel di atas, nilai rata-rata error pada hasil pembacaan sensor DO adalah sebesar $0,49 \%$. Nilai error tersebut masih dalam batas toleransi sehingga dapat dilanjutkan diolah dalam mikrokontroler untuk pengendalian. Adapun laju penurunan kadar DO ditunjukkan pada Tabel 2.

Tabel 2. Laju Penurunan Kadar DO tanpa Sistem Kendali.

\begin{tabular}{cccc}
\hline No. & $\begin{array}{c}\text { Waktu } \\
(\text { WIB })\end{array}$ & $\begin{array}{c}\text { Kaju } \\
(\mathbf{m g} / \mathbf{L})\end{array}$ & $\begin{array}{c}\left(\frac{\Delta \mathbf{m g} / \mathbf{L}}{\Delta \text { detik }}\right) \\
\text { Penurunan }\end{array}$ \\
\hline $\mathbf{1}$ & $11: 51: 58-11: 52: 05$ & $2,22-2,19$ & 0,004 \\
$\mathbf{2}$ & $11: 52: 05-11: 52: 12$ & $2,19-2,16$ & 0,004 \\
$\mathbf{3}$ & $11: 52: 12-11: 52: 23$ & $2,16-2,13$ & 0,002 \\
$\mathbf{4}$ & $11: 52: 23-11: 52: 34$ & $2,13-2,11$ & 0,002 \\
$\mathbf{5}$ & $11: 52: 34-11: 52: 44$ & $2,11-2,08$ & 0,003 \\
\hline \multicolumn{4}{c}{ Rata-rata penurunan } \\
\hline
\end{tabular}

Berdasarkan tabel tersebut, didapatkan rata-rata laju penurunan kadar DO adalah 0,003 $\mathrm{mg} / \mathrm{L}$ setiap detiknya. Penurunan kadar DO dapat dikendalikan dengan mengaktifkan pompa compressor sehingga dapat memperhambat penurunan kadar DO dan menaikkan kadar DO dengan hasil laju penurunan kadar DO setelah pengendalian ditunjukkan pada Tabel 3 .
Tabel 3. Laju Penurunan Kadar DO menggunakan Sistem Kendali

\begin{tabular}{cccc}
\hline No. & $\begin{array}{c}\text { Waktu } \\
\text { (WIB) }\end{array}$ & $\begin{array}{c}\text { Kajua DO } \\
(\mathbf{m g} / \mathbf{L})\end{array}$ & $\begin{array}{c}\text { Penurunan } \\
\left(\frac{\Delta \boldsymbol{m} / \mathbf{L}}{\Delta \text { detik }}\right)\end{array}$ \\
\hline $\mathbf{1}$ & $12: 09: 21-12: 09: 22$ & $3,20-3,20$ & 0 \\
$\mathbf{2}$ & $12: 09: 22-12: 09: 23$ & $3,20-3,20$ & 0 \\
$\mathbf{3}$ & $12: 09: 23-12: 09: 24$ & $3,20-3,20$ & 0 \\
$\mathbf{4}$ & $12: 09: 24-12: 09: 25$ & $3,20-3,32$ & $-0,12$ \\
$\mathbf{5}$ & $12: 09: 25-12: 09: 26$ & $3,32-3,60$ & $-0,28$ \\
\hline \multicolumn{4}{r}{} \\
\hline
\end{tabular}

Pada tabel tersebut menunjukkan bahwa laju penurunan saat menggunakan sistem kendali bernilai minus yang berarti berkebalikan dari laju penurunannya yaitu kadar oksigen mengalami kenaikan.

\subsection{Hasil Kalibrasi dan Pengujian Sensor Arus}

Sensor arus yang digunakan adalah Sensor Arus ACS712 telah dikalibrasi dengan melakukan pembacaan nilai ADC pada mikrokontroler dan nilai arus yang terukur pada amperemeter dengan hasil ditunjukkan pada Gambar 6 Hasil Pembacaan Arus dengan Multimeter dan ADC pada Sensor ACS712. Hasil pembacaan ADC yang dihasilkan pin analog output sensor arus ACS712 menunjukkan berbanding lurus dengan arus yang diukur menggunakan multimeter dapat dilihat pada Gambar 6.

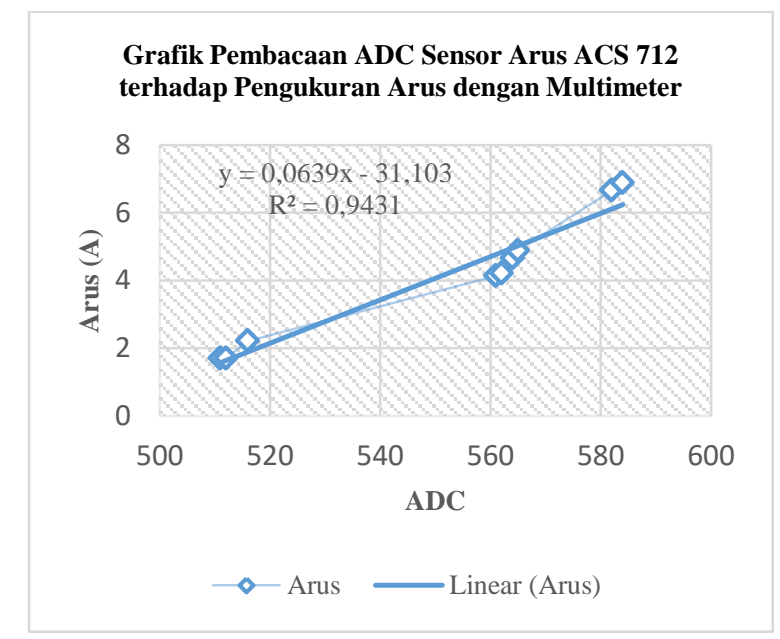

Gambar 6. Grafik Pembacaan ADC Sensor Arus ACS

712 terhadap Pengukuran Arus dengan Multimeter

Hubungan pembacaan ADC dan arus sebenarnya dapat dituliskan dengan persamaan sesuai pada grafik linearitas di atas sebagai berikut:

$$
y=0,0639 x-31,103
$$

Berikut ini perbandingan hasil pengujian pembacaan arus menggunakan sensor arus ACS 712 dengan Multimeter (Nilai Arus sebenarnya) sebagai berikut. 
Tabel 4. Hasil Pengujian Sensor Arus

\begin{tabular}{cccc}
\hline No. & $\begin{array}{c}\text { Pembacaan Arus } \\
\text { ACS712 (A) }\end{array}$ & $\begin{array}{c}\text { Pengukuran Arus } \\
\text { dengan Multimeter } \\
(\mathbf{A})\end{array}$ & $\begin{array}{c}\text { Error } \\
(\boldsymbol{\%})\end{array}$ \\
\hline $\mathbf{1}$ & 3,330 & 3,110 & 7,074 \\
$\mathbf{2}$ & 3,000 & 2,980 & 0,671 \\
$\mathbf{3}$ & 2,959 & 2,950 & 0,305 \\
$\mathbf{4}$ & 2,885 & 2,900 & 0,517 \\
$\mathbf{5}$ & 2,510 & 2,430 & 3,292 \\
\hline \multicolumn{3}{c}{ Rata-rata (\%) } \\
\hline \multicolumn{3}{c}{}
\end{tabular}

Berdasarkan data pada tabel di atas, nilai rata-rata error pada hasil pembacaan sensor arus ACS712 adalah sebesar $2,372 \%$.

\subsection{Hasil Desain Sinyal Respon Pompa dengan Metode Ziegler Nichols}

Penentuan parameter kendali PID menggunakan metode Ziegler Nichols untuk memenuhi kebutuhan sistem PID yang optimal [8] dengan hasil desain pompa ditunjukkan pada Gambar 7.

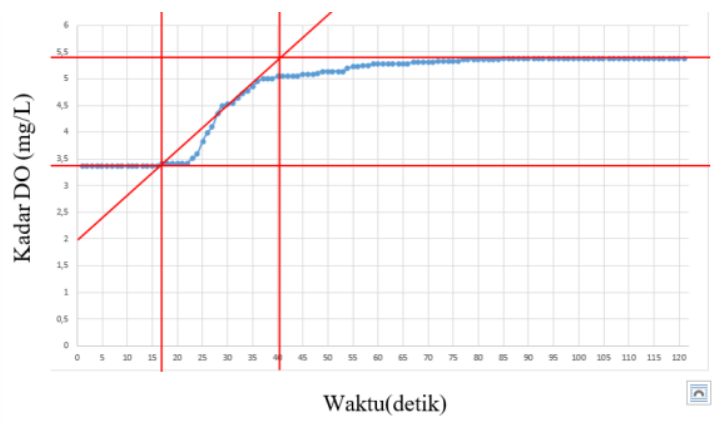

Gambar 7. Grafik Hasil Desain Sinyal Pompa Kompresor

Grafik hasil desain di atas menunjukkan nilai $\mathrm{K}=2, \mathrm{~L}=$ 17, dan $\mathrm{T}=23$. Dari nilai $\mathrm{K}, \mathrm{L}, \mathrm{T}$ tersebut dapat dihitung nilai $\mathrm{Kp}$, $\mathrm{Ti}$, dan $\mathrm{Td}$ dengan berlandaskan rumus perhitungan pada Gambar 8.

\begin{tabular}{|c|c|c|c|}
\hline $\begin{array}{c}\text { Type of } \\
\text { Controller }\end{array}$ & $K_{p}$ & $T_{i}$ & $T_{d}$ \\
\hline P & $\frac{T}{L}$ & $\infty$ & 0 \\
\hline PI & $0.9 \frac{T}{L}$ & $\frac{L}{0.3}$ & 0 \\
\hline PID & $1.2 \frac{T}{L}$ & $2 L$ & $0.5 L$ \\
\hline
\end{tabular}

Gambar 8. Perhitungan untuk menentukkan $\mathrm{Kp}, \mathrm{Ti}, \mathrm{Td}[9]$

$K p=1,2 \frac{T}{K L}=0,812$

$T i=2 L=34, K i=\frac{K p}{T i}=\frac{0,0812}{34}=0,002$

$T d=0,5 L=8,5, K d=K p \times T d=0,812 \times 8,5=0,7$
Nilai Kp, Ki, dan Kd dengan masing-masing nilai 0,812, 0,002 dan 0,7 tersebut dapat dimasukkan ke dalam persamaan PID sebagai berikut.

$$
\begin{aligned}
& u(t)=K_{p} e(t)+\frac{K_{p}}{T_{i}} \int e(t) d t+K_{p} T_{d} \frac{d(e[t])}{d t} \\
P I D= & 0,812 \cdot e(t)+0,002 T s[e(t-1)+e(t)]+ \\
& 0,7 \cdot \frac{e(t)-e(t-1)}{T s}
\end{aligned}
$$

Perhitungan tersebut dilakukan oleh mikrokontroler sesuai dengan program untuk menghasilkan nilai keluaran PID. Keluaran tersebut sebagai kendali kecepatan pompa kompresor pemasok kadar DO.

Grafik hasil pengendalian tersebut ditunjukkan pada Gambar 9. Grafik Hasil Pengendalian Kadar DO dengan Kendali PID - Set Point 4 mg/L.

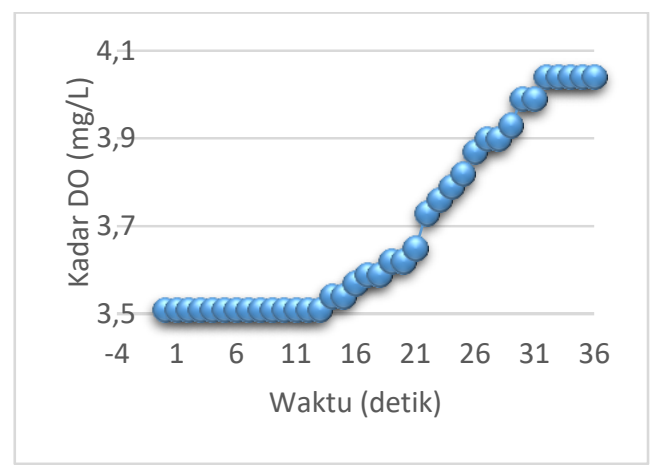

Gambar 9. Grafik Hasil Pengendalian kendali PID

Pengujian juga dilakukan pada set point $5 \mathrm{mg} / \mathrm{L}$ dan 6 $\mathrm{mg} / \mathrm{L}$ dengan hasil yang ditunjukkan pada Gambar 10 dan Gambar 11 Grafik Hasil Pengendalian Kadar DO dengan Kendali PID - Set Point 5 mg/L dan 6 mg/L.

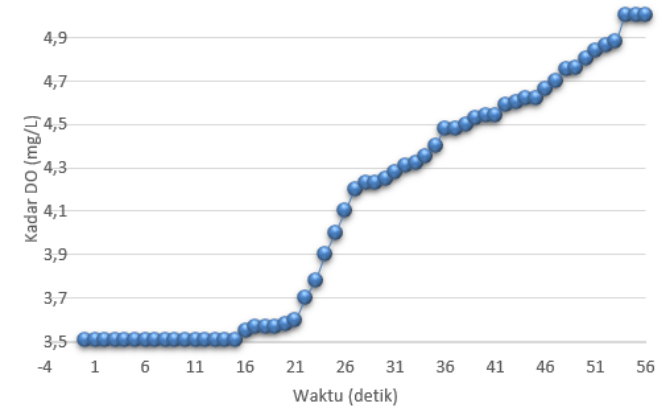

Gambar 10. Grafik Hasil Pengendalian Kadar DO dengan Kendali PID - Set Point 5 mg/L

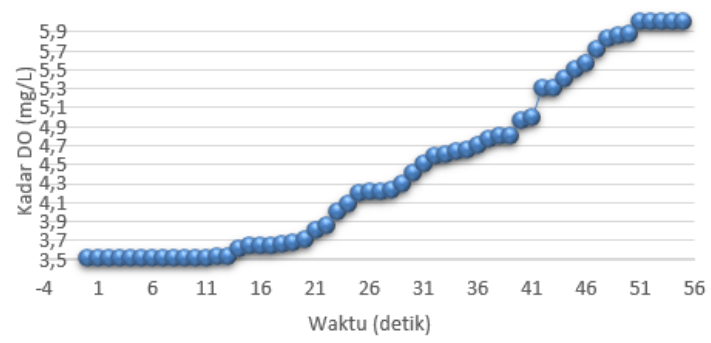

Gambar 11. Grafik Hasil Pengendalian Kadar DO dengan Kendali PID - Set Point 6 mg/L. 
Karakteristik kendali PID dapat didapatkan dari rumus berikut:

- Persentase Overshoot

$\%$ Overshoot $=\left(\frac{\text { Peak Value-Steady State Value }}{\text { Steady State Value }} \times 100 \%\right)$

- Rise Time

Rise Time $=10 \%-90 \%$ dari waktu steady state

- Settling Time

Settling Time $=2 \%$ dari waktu masuk steady state

Berdasarkan data ketiga grafik pada Gambar 9, 10, dan 11 didapatkan hasil karakterisk PID yang ditunjukkan pada Tabel 5. Karakteristik PID pada Set Point 4, 5, dan $6 \mathrm{mg} / \mathrm{L}$.

Tabel 5. Karakteristik PID pada Set Point 4, 5, dan $6 \mathrm{mg} / \mathrm{L}$

\begin{tabular}{cccccc}
\hline No. & $\begin{array}{c}\text { Set } \\
\text { Koint } \\
\text { Kadar } \\
\text { DO } \\
(\mathbf{m g} / \mathrm{L})\end{array}$ & $\begin{array}{c}\text { Persentase } \\
\text { Overshoot } \\
(\%)\end{array}$ & $\begin{array}{c}\text { Rise } \\
\text { Time } \\
(\mathbf{s})\end{array}$ & $\begin{array}{c}\text { Settling } \\
\text { Time } \\
(\mathbf{s})\end{array}$ & $\begin{array}{c}\text { Waktu } \\
\text { mencapai } \\
\mathbf{4} \mathbf{~ m g / L} \\
(\mathbf{s})\end{array}$ \\
\hline 1 & $4 \mathrm{mg} / \mathrm{L}$ & 0 & 25,6 & 32,6 & 31 \\
2 & $5 \mathrm{mg} / \mathrm{L}$ & 0 & 44,8 & 57,1 & 24 \\
3 & $6 \mathrm{mg} / \mathrm{L}$ & 0 & 40,8 & 52,0 & 23 \\
\hline
\end{tabular}

Berdasarkan data pada Tabel 5, Rise time dari pengendalian sistem dengan set point $5 \mathrm{mg} / \mathrm{L}$ memerlukan waktu yang lebih lama dibandingkan rise time hasil kendali PID pada set point $4 \mathrm{mg} / \mathrm{L}$ dan 6 $\mathrm{mg} / \mathrm{L}$. Namun, pada sistem dengan set-point $6 \mathrm{mg} / \mathrm{L}$, waktu yang dibutuhkan hingga kadar DO mencapai 4 $\mathrm{mg} / \mathrm{L}$ adalah 23 detik. Hal tersebut lebih cepat dibandingkan set point yang diatur sebesar $4 \mathrm{mg} / \mathrm{L}$ dan $5 \mathrm{mg} / \mathrm{L}$ tetapi saat kadar DO mencapai $4 \mathrm{mg} / \mathrm{L}$ pompa tetap akan aktif hingga mencapai $6 \mathrm{mg} / \mathrm{L}$. Hal tersebut dapat disesuaikan sesuai kebutuhan antara penghematan efisiensi daya dan kecepatan dalam mencapai set point.

\subsection{Hasil Pengujian Sistem secara Keseluruhan}

Hasil pengujian keseluruhan sistem ditunjukkan pada Tabel 6. Saat kadar DO di bawah $4 \mathrm{mg} / \mathrm{L}$ dan saat kadar DO di atas $4 \mathrm{mg} / \mathrm{L}$.

Tabel 6. Hasil Pengujian Keseluruhan Sistem

\begin{tabular}{ccccc}
\hline No. & $\begin{array}{c}\text { Kadar DO } \\
(\mathbf{m g} / \mathbf{L})\end{array}$ & $\begin{array}{c}\text { Arus } \\
(\mathbf{A})\end{array}$ & $\begin{array}{c}\text { Nilai PWM } \\
\text { Pompa PLN }\end{array}$ & $\begin{array}{c}\text { Nilai PWM } \\
\text { Pompa Solar } \\
\text { Panel }\end{array}$ \\
\hline 1 & 3,07 & 5,70 & 0 & 255 \\
2 & 3,07 & 5,70 & 24 & 255 \\
3 & 3,48 & 1,11 & 18 & 240 \\
4 & 3,99 & 1,03 & 2 & 2 \\
5 & 4,04 & 0 & 0 & 0 \\
\hline
\end{tabular}

Data tersebut menunjukkan saat Kadar DO kurang dari $4 \mathrm{mg} / \mathrm{L}$, arus lebih dari $1 \mathrm{~A}$, maka nilai PWM Pompa bersumber Solar Panel sesuai dengan hasil program pengendalian PID terhadap kadar DO yaitu 255, saat selama 30 detik pompa bersumber dari solar panel belum dapat memasok oksigen hingga mencapai set point (4 mg/L), pompa bersumber dari PLN akan menyala dengan nilai set point sesuai dengan pengendalian sesuai pada tabel nomor 2 yaitu saat sistem berjalan seteleh 31 detik. Semakin tinggi kadar DO, maka kecepatan pompa semakin berkurang. Ketika kadar DO lebih dari $4 \mathrm{mg} / \mathrm{L}$, maka pompa tidak ada yang aktif.

Berdasarkan hasil pengujian sistem pengendalian sinkronisasi sumber daya pompa tersebut dapat diperhitungkan efisiensi minimum dan maksisum daya dengan rumus sebagai berikut:

$$
\text { (efisiensi) } \eta=\frac{\text { energi } \text { keluaran }}{\text { energi } \text { masukkan }} \times 100 \%
$$

- Efisiensi Minimum

$$
\text { (efisiensi) } \eta \text { minimum }=\frac{12 V \times 1,03 \mathrm{~A}}{12 \mathrm{~V} \times 10 \mathrm{~A}} \times 100 \%=10,3 \%
$$

- Efisiensi Maksimum

$$
\begin{aligned}
\text { (efisiensi) } \eta \text { maksimum } & =\frac{12 V \times 5,70 \mathrm{~A}}{12 V \times 10 \mathrm{~A}} \times 100 \% \\
& =57,0 \%
\end{aligned}
$$

\section{KESIMPULAN}

Sistem mampu mendeteksi oksigen terlarut dengan tingkat error 0,49\%. Pengendalian kadar oksigen terlarut dilakukan dengan metode kendali PID yang memiliki karakteristik PID pada set point kadar DO 4 $\mathrm{mg} / \mathrm{L}$ yaitu, nilai $\mathrm{Kp} \mathrm{0,812,} \mathrm{Ki} \mathrm{0,002,} \mathrm{dan} \mathrm{Kd} \mathrm{0,7}$, overshoot $0 \%$, rise time $25,6 \mathrm{~s}$, dan settling time $32,6 \mathrm{~s}$, serta sinkronisasi otomatis sumber daya hybrid PLN dan PLTS dengan efisiensi minimum 10,3\% dan efisiensi maksimum $57 \%$.

\section{UCAPAN TERIMA KASIH}

Terima kasih penulis sampaikan kepada Politeknik Manufaktur Bandung atas dukungan dan fasilitas yang diberikan sehingga penelitian ini dapat terselenggara dengan baik.

\section{DAFTAR PUSTAKA}

[1] A. Basrah, dkk, "Pemasangan Sistem Hybrid sebagai Penggerak Pompa Air", JTEV, Universitas Negeri Padang, 2019.

[2] Nuryanti, Bolo Dwiartomo, Ayi Ruswandi, "Analisis Daya yang dihasilkan Turbin Angin Tipe Windmill Pada Sistem Aerasi Tambak Udang” JTRM Vol 1 No 1, 2019.

[3] "Pasang PLTS Atap kini bisa Rp 10 juta per kWp, investasinya semakin ekonomis" (kontan.co.id), 2020.

[4] E. Budiyanto, Interviewee, Tambak Udang Vanname Pantai Trisik. [Wawancara]. 12 January 2019. 
[5] R. Ikhsan, "Kajian Teknis dan Ekonomis Penerapan Sistem Hibrid BAPV-PLN pada Gedung Politeknik Aceh", Politeknik Aceh, 2019.

[6] A. Fiyanti, "Sistem Otomasi Kincir Air Untuk Respirasi Udang Tambak Menggunakan Sensor Dissolved Oxygen (Do)," Universitas Lampung, Bandar Lampung, 2017.

[7] D. Ramdani, "Realisasi Prototipe Sistem Peningkatan Produksi Budidaya Udang dengan Pemantauan dan Pengendalian Suhu, Kadar Oksigen, dan PH Air secaraa Otomatis berbasis IoT" Politeknik Negeri Bandung, Bandung, 2015.

[8] N. Allu, S. Salu, "Aplikasi Penalaan dengan Metode Ziegler Nichols di Perancangan Pengendali PID pada Putaran Motor DC" Prosiding Seminar Nasional Universitas Kristen Indonesia Paulus Makassar, 2018S.

[9] S. Bakar, Feriyonika, "Desain Kendali PID dengan Ziegler Nichols". 